\title{
PARTICULATE BEHAVIOR IN A CONTROLLED-PROFILE PULVERIZED COAL-FIRED REACTOR: A STUDY OF COUPLED TURBULENT PARTICLE DISPERSION AND THERMAL RADIATION TRANSPORT

Quarterly Technical Progress Report

For Period September 15, 1995 to December 14, 1995

Mardson Queiroz and Brent W. Webb

Brigham Young University

Provo, UT 84602

\begin{abstract}
Prepared for the Unlted States Department of Energy
PIttsburgh Energy Technology Center (PETC)
\end{abstract}

Under Contract No. DE-FG22-91PC91308

"US/DOE Patent Clearance is not required prior to the publication of this document" 


\section{DISCLAIMER}

This report was prepared as an account of work sponsored by the United States Government. Neither the United States nor the United States Department of Energy, nor any of their employees nor any of their contractors, subcontractors, or their employees, makes any warranty, expressed or implied, or assumes any legal liability or responsibility for the accuracy, completeness, or usefulness of any information, apparatus, product or process disclosed, or represents that its use would infringe privately owned rights. 


\section{FORWARD}

This report summarizes technical progress during the seventeenth quarter. (September 15, 1995 to December 14, 1995) of a three-year study conducted for the Department of Energy (DOE) under contract number DE-FG22-91PC91308. The principal investigators for this work are Dr. Mardson Queiroz and Dr. Brent W. Webb; Dr. Clifford Smith is the technical representative for DOE. 


\section{TABLE OF CONTENTS}

PAGE

DISCLAIMER

FORWARD

1. OBJECTIVES AND SCOPE

1.1 BACKGROUND

1.2 OBJECTIVES 1

1.3 TECHNICAL APPROACH

2. SUMMARY OF TECHNICAL PROGRESS ․ 2

2.1 The SSF Model for Particle Dispersion in Turbulent Flows 2

3. REFERENCES 4

$\begin{array}{ll}\text { 4. APPENDIX } & 5\end{array}$ 


\begin{abstract}
During the seventeenth quarter progress has been made in the area of modeling turbulent particle dispersion. This report describes the Stochastic-Separated-Flow (SSF) algorithm which is implemented for the numerical modeling of turbulent dispersion.
\end{abstract}




\section{OBJECTIVES AND SCOPE}

\subsection{BACKGROUND}

Improved understanding of the fundamental processes involved in pulverized-coal combustion is needed to make the energy extraction more efficient and the combustion byproducts environmentally safe. While the characterization of the local particulate behavior (concentration, size, and velocity) is important to the understanding of virtually all processes in a pulverized coal-fired furnace, it influences in a more direct way the turbulent particle dispersion and thermal radiation heat transfer. Yet the local particulate dynamics have gone relatively unaddressed, primarily because of lack of adequate instrumentation to carry out such a study. With recent advances in optical techniques such an effort is now possible. This proposal seeks to characterize the local particulate concentration, velocity, and size distribution in a wellcontrolled, parametrically-varied laboratory-scale reactor using a new laser diagnostic technique. This newly-developed technique is the only one currently available for the investigation of aspherical particles. The particulate data will be collected simultaneously with local gas temperature and wall radiant heat flux distributions.

\subsection{OBJECTIVES}

This report describes recent progress in a fundamental, three-year investigation of the coupled problem of turbulent particle dispersion and thermal radiation transport. The project's objective is to make measurements of particle size, velocity, number density, temperature and wall radiant heat flux in a parametrically-controlled reactor presently existent at Brigham Young University (BYU). Although the study proposed here is primarily designed to provide experimental data not currently available for the evaluation of turbulent particle dispersion and radiation models, comparisons of analytical predictions and the experimental data obtained will be performed, using appropriate submodels integral to comprehensive pulverized-coal combustion codes existent at BYU.

\subsection{TECHNICAL APPROACH}

To accomplish the above objectives, the project is divided in the following tasks:

- Design and fabrication of a modified section for the BYU controlled-profile reactor, which will allow access of several probes to be used in the proposed study.

- Design and fabrication of a two-color pyrometer and cooled probe for local particulate temperature measurement.

- Characterization of the non-reacting turbulent flow field in the reactor using the PCSV-P probe, which will serve as an input during the turbulent particle dispersion submodel validation.

- Literature review dealing with particle dispersion and radiation transport in support of the model validation effort.

- Perform the parametrically-controlled measurements in the controlled-profile reactor.

- Experimental data analysis.

- A comprehensive comparison of experimental data and model predictions.

- Final report. 


\section{SUMMARY OF TECHNICAL PROGRESS}

\subsection{The SSF Model for Particle Dispersion In Turbulent Flows}

The particles in the SSF model are treated in the Lagrangian framework. The calculation procedure consists in determining the gas velocity field and then calculating the particle trajectories based on it. To calculate the particle trajectories, it is necessary to solve the particle momentum equation (Eq. (1)).

$$
\frac{d u_{p: i}}{d t}=\frac{1}{\tau_{p}}\left(u_{f: i}-u_{p ; i}\right)+g_{i},
$$

where the particle relaxation time $\left(\tau_{p}\right)$ is given as

$$
\tau_{p}=\frac{m_{p}}{3 \pi d_{p} \mu_{f}} \frac{1}{\left(1+0.15 \operatorname{Re}_{p}^{0.687}\right)} .
$$

In Eq. (2), $R e_{p}$ is the particle Reynolds number, calculated with the gas kinematic viscosity, the particle-to-gas relative velocity, and the diameter of the particle as the characteristic length scale. Equation (1) is a nonlinear, first-order, nonhomogeneous, ordinary differential equation. The exact analytical solution of this equation is not trivial, but if the time steps are considered to be small enough that $\tau_{p}$ remains constant during the integration interval, Eq. (1) can be solved analytically as a linear equation. The integration of this equation over a small time step gives

$$
\left.\begin{array}{l}
u_{p ; i}^{N E W}=u_{f ; i}+\left(u_{p ; i}^{O L D}-u_{f ; i}\right) e^{-\Delta t / \tau_{p}}+g_{i} \tau_{p}\left[1-e^{-\Delta z / \tau_{p}}\right] \\
x_{p ; i}^{N E W}=x_{p ; i}^{O L D}+\frac{\Delta t}{2}\left(u_{p ; i}^{N E W}+u_{p ; i}^{O L D}\right)
\end{array}\right\} .
$$

In the SSF model, the gas velocity $\left(u_{f ; i}\right)$ that appears in Eq. (3) is the instantaneous gas velocity, and the issue is then how to estimate the fluctuating part of the gas velocity. Another important factor to determine is the appropriate time step for the solution of Eq. (3).

The SSF model implemented in this work estimates the fluctuating component of the gas velocity and the time step required to solve Eq. (3) by accounting for consecutive eddy-particle interactions. The particle interacts with a series of eddies as it is tracked in the Lagrangian framework. Each eddy that the particle interacts with is described by a fluctuating velocity $\left(u_{f}^{\prime}\right)$, a time scale $\left(\tau_{l}\right)$ called the eddy lifetime, and a length scale $\left(l_{e}\right)$ known as the eddy characteristic size. The particle will interact with a particular eddy for a time that is the minimum of the eddy lifetime and eddy transit time $\left(t_{c}\right)$. Thus the expression for the time step (interaction time) is given by

$$
t_{\text {int }}=\Delta t=\min \left(\tau_{l}, t_{c}\right) \text {. }
$$

The eddy transit time, the time a particle will take to cross an eddy of size $l_{e}$, is mathematically expressed by

$$
t_{c}=-\tau_{p} \ln \left(1-\frac{l_{e}}{\tau_{p}\left|u_{f ; i}-u_{p ; i}\right|}\right),
$$

where the magnitude of the relative velocity $\left(\left|u_{f ; i}-u_{p ; i}\right|\right)$ during the eddy-particle interaction is approximated by its value at the start of the new interaction (Shuen et al., 1983).

The eddy lifetime and the eddy characteristic size needed along the particle trajectory are estimated from the local turbulence properties. A general expression for these two scales in isotropic flows has the form

$$
\tau_{f L}=A \frac{k}{\varepsilon} \text { and } l_{e}=A \sqrt{\frac{2}{3}} \frac{k^{3 / 2}}{\varepsilon},
$$

where $A$ is a constant. The value of $A$ used in the literature ranges from 0.135 to 0.41 (Milojevic, 1990). The constant is determined either by some scaling analysis (Calabrese and Middleman, 1979; Gosman and loannides, 1981) or from experimental data (Chen and Crowe, 1984). The value of A used here, 0.3, 
is based on the computer optimization study of Milojevic (1990), who used the experimental data of Snyder and Lumley (1971) to determine the value of A.

In the SSF formulation, the fluctuating gas velocity vector acting on the particle during its interaction with a particular eddy is assumed to be constant over the interaction time. This fluctuating gas velocity vector is randomly sampled from a probability density function (PDF) that is obtained from the local turbulence properties. This PDF, required along the particle trajectory, is assumed to be Gaussian. Thus it is sufficient to estimate the covariance matrix of the fluctuating gas velocity vector at each particle location in order to construct the PDF. Three different methods are considered in the present study to estimate this matrix. The first one assumes isotropy, meaning that the component of the fluctuating velocity in one direction does not have any influence in the other (perpendicular) direction. The variance in this case can be expressed as

$$
\overline{u_{f: i}^{\prime 2}}=\frac{2}{3} k \text {. }
$$

The second technique makes use of the Boussinesq hypothesis embedded in the eddyviscosity turbulence models to estimate a component of the fluctuating velocity once the other (perpendicular) component of the fluctuating velocity is determined. To do that, the modeled Reynolds stresses are invoked in the form of the Boussinesq hypothesis:

$$
\bar{\rho} \overline{u_{f ; i}^{\prime} u_{f ; j}^{\prime}}=\frac{2}{3} \delta_{i j} \bar{\rho} k-\mu_{t}\left(\frac{\partial \bar{u}_{f ; i}}{\partial x_{j}}+\frac{\partial \bar{u}_{f ; j}}{\partial x_{i}}\right)
$$

The above equation predicts the tangential correlations $\left(\overline{u_{f ; i}^{\prime} u_{f ; j}^{\prime}} ; i \neq j\right)$ fairly well, but the normal correlations $\left(u_{f ; i}^{\prime 2}\right)$ differ significantly from the experiments (Picart et al., 1986). Thus in order to better estimate the normal correlations, the second-order algebraic relations proposed by Rodi (1979) are considered as the third method. The expression used to estimate the normal correlations as per the above mentioned algebraic relations is

$$
\overline{u_{f ; i}^{\prime 2}}=\frac{2 k}{3}-\frac{k}{\Phi / \bar{\rho}-\varepsilon+C_{1}^{\prime} \varepsilon} \times\left\{\begin{array}{l}
\left(1-\gamma_{1}\right)\left(2 \overline{u_{f ;}^{\prime} u_{f ; k}^{\prime}} \frac{\partial \bar{u}_{f ; i}}{\partial x_{k}}+\frac{2}{3} \Phi / \bar{\rho}\right) \\
+2 \gamma_{2} k \frac{\partial \bar{u}_{f ; i}}{\partial x_{i}}-\gamma_{3}\left(2 \overline{u_{f ; i}^{\prime} u_{f ; k}^{\prime}} \frac{\partial \bar{u}_{f ; k}}{\partial x_{i}}+\frac{2}{3} \Phi / \bar{\rho}\right)
\end{array}\right\}
$$

where the model constants $C_{1}^{\prime}, \gamma_{1}, \gamma_{2}$, and $\gamma_{3}$ are set equal to $1.8,0.76,0.18$, and 0.11 , respectively (refer to Picart et al., 1986). The tangential correlations required to solve Eq. (9) are obtained from Eq. (8). 


\section{REFERENCES}

Calabrese, R.V., and Middleman, S., 1979, "The dispersion of discrete particles in a turbulent fluid field," AlChE Journal, vol. 25, No. 6, pp. 1025-1035.

Chen, P.P., and Crowe, C.T., 1984, "On the Monte-Carlo Modeling Particle Dispersion in Turbulence," Proc. Intl. Symp. on gas-solid flows, ASME FED, vol. 10, pp. 37-41.

Gosman, A. D., and loannides, E., 1981, "Aspects of computer simulation of liquid-fuelled combustors," Presented at the AAIA 19th Aerospace Science Mtg, St Louis, Mo., Paper 81 0323.

Milojevic, D., 1990, "Lagrangian Stochastic-Deterministic (LSD) predictions of particle dispersion in turbulence," Part. Part. Syst. Charact., vol. 7, pp. 181-190.

Picart, A., Berlemont, A. and Gouesbet, G., 1986, "Modelling and predicting turbulence fields and the dispersion of discrete particles transported by turbulent flows," Int. J. Multiphase Flow, vol. 12, pp. 237-261.

Rodi, W., 1979, "Influence of buoyancy and rotation on equations for the turbulent length scale," Proceedings of the 2nd Symposium on Turbulent Shear Flows, Imperial College of London, 10.42-10.47.

Shuen, J.S., Chen, L.D., and Faeth, G.M., 1983, "Evaluation of a stochastic model of particle dispersion in a turbulent round jet," AIChE Journal, vol. 29, pp. 167-170.

Snyder, W.H., and Lumley, J.L., 1971, "Some measurements of particle velocity autocorrelation function in turbulent flow," J. Fluid Mech., vol. 48, pp. 41-71. 


\section{APPENDIX \\ REPORT DISTRIBUTION LIST}

Ms. Marilyn Keane

PM-01, MS 922-206

U.S. Department of Energy

Pittsburgh Energy Technology Center

P.O. Box 10940

Pittsburgh, PA 15236

Ms. Rhonda L. Dupree

AD-22, MS 921-118

U.S. Department of Energy

Pittsburgh Energy Technology Center

P.O. Box 10940

Pittsburgh, PA 15236

Office of Technology Transfer

Attn: Kay Downey

Mail Stop 58-M217

U.S. Department of Energy

Pittsburgh Energy Technology Center

P.O. Box 10940

Pittsburgh, PA 15236

U.S. Department of Energy

Attn: Document Control Center

Mail Stop 921-118

P.O. Box 10940

Pittsburgh, PA 15236-0940

Dr. Clifford Smith

U.S. Department of Energy

Pittsburgh Energy Technology Center

P.O. Box 10940

Pittsburgh, PA 15236 